Plant Molecular Biology 20: 175, 1992.

(C) 1992 Kluwer Academic Publishers. Printed in Belgium.

Erratum

\title{
Agrobacterium and plant genetic engineering
}

Paul J. J. Hooykaas and Rob A. Schilperoort

Clusius Laboratory, Institute of Molecular Plant Sciences, Leiden University, Wassenaarseweg 64, 2333

AL Leiden, Netherlands

Plant Molecular Biology 19: 15-38, 1992.

On page 28, in the first column, under the heading Vector Systems, lines 6 until line 7, read as follows: "Experiments in which the T-region was separated from the rest of the Ti plasmid [45, 69]."

However, they should read: "To study this, experiments were performed in which the T-region was separated from the rest of the Ti plasmid [69]." 